\title{
ROLE OF NECK IMAGING REPORTING AND DATA SYSTEM (NI- RADS) IN THE PREDICTION OF LOCAL AND REGIONAL RECURRENCE OF HEAD AND NECK SQUAMOUS CELL CARCINOMA BY CROSS SECTIONAL IMAGING MODALITIES
}

\author{
Hanaa Abdel Kader Abdel Hameed*, Zeinab Mohammed Abdel Hafeez**, Tougan \\ Taha Abdel Aziz ${ }^{*}$, Ahmed Samy Abdelrahman ${ }^{*}$ and \\ Manar Maamoun Mohamed Ashour*
}

\author{
*Radiodiagnosis, ${ }^{* *}$ Clinical \\ Oncology and Nuclear \\ Medicine, Faculty of Medicine, \\ Ain Shams University \\ Corresponding : \\ Manar Maamoun Ashour \\ Mobile: 01009768388 \\ E mail: \\ manar.ashour@gmail.com \\ Received: 29/8/2019 \\ Accepted: 26/9/2019
}

\begin{abstract}
:
Background: Detection of residual, recurrent, or second primary malignancies in head and neck cancers treated patients can be challenging. Soft tissue changes and anatomical disfigurement seen after surgery, radiotherapy, and chemotherapy can distort the anatomy of the head and neck and make post treatment imaging reporting very complex.
\end{abstract}

Aim of work: To evaluate the performance of the Neck imaging, and reporting data system template recently created by the American College of Radiology (ACR) Committee in the prediction of local and regional disease recurrence or persistence of head and neck squamous cell carcinoma after treatment by using CE MRI/ CT, and PET-CT in inconclusive cases.

Patients and Methods: 116 scans for 55patients with head and neck squamous cell cancerswere included after finishing their treatment, reporting done using the ACR NI-RADS reporting template and lexicon and NI-RADS category was assigned to each scan, the accuracy of this categorization was done by correlation with our gold standard: tissue pathological examination and/ or three months interval follow up scan.

Results: Out of the 116 scans included in our study, we had 232 targets for primary tumour sites and lymph nodes, the overall tumour recurrence have occurred in 53 targets out of the total of 232, with a total tumour recurrence rate of $22.8 \%$, the recurrence rates for each NI-RADS category for the primary tumour site were: $3.9 \%$ (2/51) for NI-RADS 1 category, 17.6\% (3/17) for NI-RADS 2a category, $18.2 \%$ (4/22) for NI-RADS $2 b$ category, and 76.9\% (20/26) for NI-RADS 3 category. Regarding the lymph nodes, the recurrence rates for the different NI-RADS categories were: $3.8 \%$ (3/80) for NI-RADS 1 category, 7.1\% (1/14) for NI-RADS 2 category, and 81.8\% (18/22) for NI-RADS 3 category. The recurrence rates for combined NI-RADS categories for both the primary tumour site and lymph nodes were (Table 7): 3.8\% (5/131) for NI-RADS 1 category, 19.6\% (10/51) for NI-RADS 2 category, and 76.2\% (38/48) for NI-RADS 3 category.

Conclusion: The performance of the ACR NI-RADS reporting system and its linked management recommendations is excellent, with statistically significant discrimination in between the different NIRADS categories for either the primary tumour site, lymph nodes and for both combined. The use of NI-RADS can help to direct the management plans towards more proper options. 
Keywords: Head and neck $(H \& N)$ cancers, Head and neck squamous cell carcinoma (HNSCC), Head and Neck Imaging Reporting and Data System (NI-RADS), The American College of Radiology (ACR), Contrast enhanced CT (CE CT), Contrast enhanced $M R I$ (CE MRI), 2-(fluorine-18)-fluoro-2-deoxy-D-glucose (18FFDG), Lymph nodes (LNs).

\section{INTRODUCTION:}

Head and neck $(H \& N)$ cancers represent the sixth most common form of cancers reported worldwide. More than $90 \%$ of them are squamous cell carcinomas. Head and neck squamous cell carcinoma (HNSCC) can arise from mucosal surface of the oral cavity, oropharynx, hypopharynx, larynx, and nasopharynx ${ }^{(\mathbf{1})}$.

A wide variety of management options for HNSCC exists including Surgery, radiation, and chemotherapy in various combinations; this depends on the TNM stage, primary site, the functional outcome and the patient's clinical condition ${ }^{(2)}$.

Despite the recent advances in the treatment options offered for $\mathrm{H} \& \mathrm{~N}$ cancers; locoregional recurrence occurs in about 20$50 \%$ of patients during the first two years after treatment ${ }^{(3)}$.

Disease recurrence is the main obstacle to long-term survival in HNSCC, so post treatment surveillance should be concerned for tumour recurrence detection at an early stage in order to provide a salvage procedure $^{(4)}$.

The complexity of head and neck anatomy added to the post treatment soft tissue changes and anatomical distortion are making the detection of residual, recurrent, or second primary malignancies in treated patients a complex process ${ }^{(5)}$.

The ACR Intersociety Committee Summer Conference recommended the universal standardized use of report templates. A multidisciplinary team created a standardized template for surveillance of post-treatment $\mathrm{H} \& \mathrm{~N}$ cancers with linked management options, and so the Head and Neck Imaging Reporting and Data System (NIRADS) was developed for surveillance of patients with treated H\&N cancers ${ }^{(6)}$.

\section{AIM OF WORK:}

To assess the performance of the NIRADS system template recently created by the ACR Committee in the prediction of local and regional disease recurrence or persistence of head and neck squamous cell carcinoma after treatment by using different cross-sectional imaging modalities.

\section{PATIENTS AND METHODS:}

A total of 55 patients who finished their treatment for HNSCC were referred from Ain Shams university hospital oncology hospital, 116 follow up scans done to them in Ain Shams University Hospital, Radiology Department, these scans included 50 CE MRI scans, 48 CE CT scans and 18 PET CT scans, and follow up done up to 12 months to them, from the period between November 2017 and April 2019.

Exclusion Criteria:

- Cases of H\&N cancers other than squamous cell carcinoma.

- Patients with renal impairment (Gadolinium can't be given with estimated glomerular filtration rate $<30$ $\mathrm{ml} / \mathrm{min} / 1.73 \mathrm{~m} 2$, and serum creatinine above $2.0 \mathrm{mg}$ for iodinated contrast material should not be administered).

- Patients known to have allergy to contrast mediumand patients with 
contraindications for MRI, e.g. ferromagnetic implants as pacemakers.

Ethical Considerations;

- An informed consent was obtained explaining the procedure details, and possible complications.

- Risks and complications:

For CE MRI: the hazards of the contrast agent include; coldness, warmth, or pain at the injection site, nausea, vomiting, headache, paraesthesia, and the rare nephrogenic systemic fibrosis (NSF) which is a disease of fibrosis of the skin and internal organs caused by gadolinium injection in patients who have renal insufficiency.

For CE CT and PET CT: the serious uncommon side effects of the iodinated contrast agent include; allergic anaphylactic or non-allergic anaphylactic, contrast induced acute kidney injury, and arrhythmia.

For PET CT: Radiation can be hazardous to foetuses. The administered 18F-FDG might be excreted in breast milk, and the scan should be delayed unless needed urgently.

\section{Study Tools:}

- Full history taking and full dedicated clinical examination.

- Patients scanned at 8-week baseline after treatment, re scanning three months later done in case of negative findings and a third scan done six months later in case of negative findings.

- CE MRI/ CT or PET- CT scanning were done; the choice of the modality tailored according to each patient's condition and tolerance, considering the primary tumour site, and questions need to be answered by the clinicians.

- NI-RADS template: Findings were categorized into one of four categories followed by further action (biopsy) or follow up according to the template recommendations (Table 1).

- Criteria for tumour recurrence included the following:(7)

1) Biopsy positive for squamous cell carcinoma,

2) Evidence of disease progression on subsequent imaging (per Response Evaluation Criteria in Solid Tumours Criteria),

3) Obvious tumour on clinical examination.

- To confirm the lack of tumour recurrence, the following must have been fulfilled:

1. Negative findings on follow-up imaging at least 6 months after the index scan with,

2. No evidence of recurrence on clinical follow-up for at least 6 months, or

3. Biopsy of an abnormality detected on an imaging scan with pathology results negative for tumour.

- Study Procedures:

- Patient Preparation:

For all modalities informed consent was obtained after detailed explanation and renal functions checked before the procedure, one ante-cubital wide bore intravenous cannula was inserted.

For patients underwent CE MR scan:

- Exclusion of any hazards like pacemaker implantation done first.

For patients underwent CE CT scan:

- Patients got well hydration and were screened for history of iodinated contrast material allergy, metformin use, and renal disease (Intravenous contrast material should not be administered when the serum creatinine level is above $2.0 \mathrm{mg} / \mathrm{dl})$. 
For patients underwent PET CT:

- Before the procedure the patients were fasting for 4-6 hours except for water. The patient has been seated in a quiet and dimly lit room before the administration of 18F-FDG, and blood glucose level checked and must have been less than $200 \mathrm{mg} / \mathrm{dl}$.

\section{Scanning parameters and imaging acquisition:}

Some modifications with limited sequences were done depending on the disease presentation and the patient's condition to reduce scan times in case of patient's discomfort or distress.

CE MRI:

- Machine: MRI scans were performed on a 1.5 T MRI Philips Achieva scanner.

- The patient was positioned supine, and a special dedicated coil was used. Scan time was 18- 25 minutes, field of view: AP 230, and slice thickness: $4 \mathrm{~mm}$

- Morphological sequences included precontrast axial T1 WIs (TE $=21 \mathrm{~ms}, \mathrm{TR}=$ $633 \mathrm{~ms})$, coronal $\mathrm{T} 1(\mathrm{TE}=14, \mathrm{TR}=$ 555), axial T2 WIs (TE $=110 \mathrm{~ms}$, TR $=7039 \mathrm{~ms}$ ), and sagittal T2 drive WI $(\mathrm{TE}=100, \mathrm{TR}=3196.7)$, All these sequences are single shot spin echo, and also coronal T2 STIR $(\mathrm{TR} / \mathrm{TI}=$ $3500 / 150$, TE $=80 \mathrm{~ms}$ ) and axial echoplanner DWI study performed with $3 \mathrm{~b}$ values.

- A dose of $0.1 \mathrm{mmol} / \mathrm{kg}$ gadolinium was administered by injector at a flow rate 2-3 $\mathrm{ml} / \mathrm{sec}$ followed by post-contrast dynamic sequences, and T1 WIs in axial, sagittal, and coronal.

CE CT:

- Machine: 128-row MDCT scanner (GE 128, Optima 660, USA).

- The patient positioned with arms down. FOV: $28 \mathrm{~cm}$. $100 \mathrm{ml}$ of iodinated contrast agent was injected; at a rate of
1-1.5 $\mathrm{ml} / \mathrm{sec}$ and scanning done $80-100$ sec after the start of the contrast agent injection.

- Axial images from the frontal sinuses through the mediastinum at $1.25-\mathrm{mm}$ section thickness; pitch, 0.984:1; gantry rotation, 0.7 seconds; $120 \mathrm{kv}$ (peak). The native CT-images acquired with a slice thickness of $0.6-0.75 \mathrm{~mm}$, and reformatted for display with a slice thickness of $3 \mathrm{~mm}$

PET CT:

- Machine: GE Discover 600 and 690 $\mathrm{PET} / \mathrm{CT}$ scanners

- Combined PET/CT from the skull vertex to mid-thigh was obtained 1 hour after intravenous administration of 10 $14 \mathrm{mCi}$ of FDG.

After the procedure:

- Patient's adequate hydration and follow up done, the patients underwent PET CT were instructed to limit the contact with pregnant women and children for 24 hours post procedure.

\section{Image analysis:}

CT and MR data were transferred to workstations (AW volume share 7 and 3D synapse, Fujifilm). Imaging findings analysis done using the ACR NI-RADS lexicon and reporting templates for PET-CT; $\mathrm{CT}$ and MRI scans. NI-RADS category assigned to each scan according to the template; one for primary site and one for lymph-nodes, management done according to the linked management recommendations. Confirmation of the findings and NI-RADS category was done by our gold standard which was pathological examination or follow up scan.

\section{Imaging Reporting and Data System} lexicon (8):

\section{- Non-mass-like soft tissue:}

- Non-enhancing or minimally enhancing distortion of soft tissue and fat planes $\{1\}$ 
- Masses:

- Morphology: ill-defined $\{2\}$ versus discrete $\{3\}$

- Enhancement: mild $\{2\}$ versus intense $\{3\}$

- FDG avidity: mild $\{2\}$ versus intense $\{3\}$

\section{- Mucosal abnormality:}

- Low density submucosal edema $\{1\}$

- Diffuse linear enhancement: benign radiation mucositis $\{1\}$

- Focal or mass-like mucosal enhancement or FDG uptake $\{2 \mathrm{a}\}$
- Residual nodal tissue plus no FDG $\{1\}$

- Residual nodal tissue plus mild FDG $\{2\}$

- Residual nodal tissue plus intense FDG $\{3\}$

- Lymph node, increasing size, without definite morphologically abnormal features, along with expected nodal drainage $\{2\}$

- Lymph node, increasing size, with morphologically abnormal features $\{3\}$.

- Lymph node of increasing size plus intense FDG $\{3\}$.

\section{- Lymph nodes:}

Table (1) NI-RADS reporting template and linked management recommendations (8):

\begin{tabular}{|l|l|l|l|}
\hline Category & Category & Imaging findings & Management \\
\hline & 0 & $\begin{array}{l}\text { New baseline study without any prior imaging } \\
\text { available and knowledge that primary imaging } \\
\text { exists and will become available }\end{array}$ & $\begin{array}{l}\text { Assign score in addendum after } \\
\text { prior imaging examinations } \\
\text { become available }\end{array}$ \\
\hline $\begin{array}{l}\text { No evidence of } \\
\text { recurrence }\end{array}$ & 1 & $\begin{array}{l}\text {-Expected post treatment changes } \\
\text {-Non mass like tissue distortion } \\
\text {-Low density mucosal edema (Figure 1) } \\
\text {-No abnormal FDG uptake } \\
\text {-Diffuse linear mucosal enhancement after } \\
\text { radiation }\end{array}$ & Routine surveillance \\
\hline Low suspicion & $2 \mathrm{a}$ & $\begin{array}{l}\text {-Focal mucosal enhancement but not mass like } \\
\text {-Focal mild to moderate mucosal FDG uptake }\end{array}$ & Direct visual inspection \\
\hline & $2 \mathrm{~b}$ & $\begin{array}{l}\text {-Deep ill-defined soft tissue, not discrete } \\
\text {-Little to no differential enhancement } \\
\text {-Mild to moderate FDG uptake }\end{array}$ & $\begin{array}{l}\text { Short interval follow up (3 } \\
\text { months), repeat PET }\end{array}$ \\
\hline High suspicion & 3 & $\begin{array}{l}\text {-New or enlarging primary mass or lymph-node } \\
\text {-Discrete nodule or mass with differential } \\
\text { enhancement (Figure 2) } \\
\text {-Intense focal FDG uptake }\end{array}$ & Image guided or clinical biopsy \\
\hline $\begin{array}{l}\text {-Pathologically proven or definite radiologic } \\
\text { and clinical progression }\end{array}$ & Clinical management \\
\hline
\end{tabular}

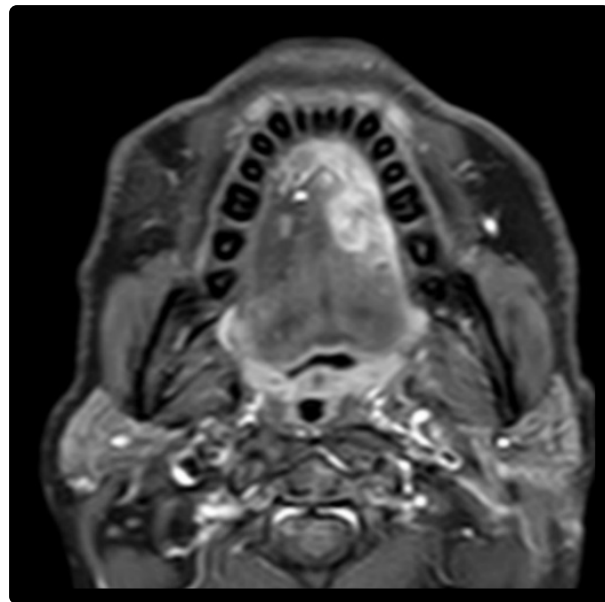

Figure 1: axial CE-CT neck at the level of the supraglottis showing predominant diffuse mucoid edema of the supraglottis in a patient underwent conservative surgery for supraglottic cancer and received RTH, keeping with NI-RADS (1) category. 
Figure 2: axial CE CT neck at the level of the tongue showing discrete enhancing mass lesion at the left anterior oral tongue, keeping with NI-RADS (3) category which was confirmed by tissue pathological examination to be residual tumorous tissue.

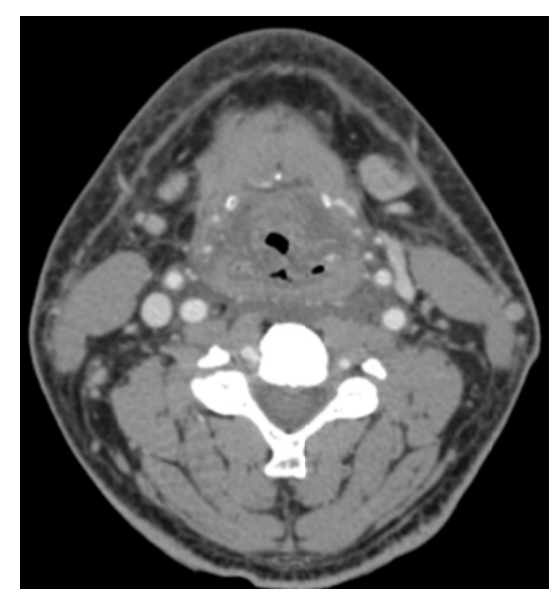

We followed up the patients according to our oncology hospital follow up programs for treated $H \& N$ cancers patients by an initial scan eight weeks after finishing therapy, then after additional three months in case of negative findings and a third follow up six months later if the findings are still negative. If the study was positive which is representing NI-RADS 3 category, further action done either by biopsy and tissue diagnosis or close follow up in cases refused biopsy or the general condition was not permitting it in proper timing. Clinical and radiological follow up interval for negative cases extended for 12 months interval post treatment.

\section{Statistical methods:}

IBM SPSS statistics (V. 25.0, IBM Corp., USA, 2017-2018) was used for data analysis. Date were expressed as median and percentiles for quantitative non-parametric measures in addition to both number and percentage for categorized data.

\section{RESULTS}

The study cohortincluded116 scans done for 55 patients; population demographics are shown in (Table 2). There were 50CE CT scans (43.1\%), 48CE MRI scans $(41.3 \%)$ and 18 PET CT (15.5\%).58 $(50 \%)$ scans were initial baseline follow up scan done eight weeks after finishing treatment; 33 (28.4\%) scans were second follow up examinations, and $25(21.5 \%)$ scans were third follow up examinations (Table 3). The pathological grading is shown in (Table 4):

Table (2) population demographics:

Table (3) scans types and number:

\begin{tabular}{|c|c|c|}
\hline Age & \multicolumn{2}{|c|}{$18-89$} \\
\hline Patients number & \multicolumn{2}{|c|}{55} \\
\hline Gender & Male & $73.6 \%$ \\
\hline & Female & $26.4 \%$ \\
\hline
\end{tabular}

\begin{tabular}{|c|c|c|}
\hline Total scans number & 116 & \\
\hline \multirow{3}{*}{ Scan type } & MRI & $48(41.3 \%)$ \\
\cline { 2 - 3 } & CT & $50(43.1 \%)$ \\
\cline { 2 - 3 } & PET CT & $18(15.5 \%)$ \\
\hline \multirow{2}{*}{ Scan order } & First follow up & $55(47.5 \%)$ \\
\cline { 2 - 3 } & Second follow up & $36(31 \%)$ \\
\cline { 2 - 3 } & Third follow up & $25(21.5 \%)$ \\
\hline
\end{tabular}


Role of neck imaging reporting and data system (ni-rads) in the prediction of local and regional..

Table (4) tumour pathological grading:

\begin{tabular}{|c|c|c|c|}
\hline \multirow{3}{*}{$\begin{array}{c}\text { Tumour } \\
\text { grade }\end{array}$} & Low & Count & 18 \\
\cline { 2 - 4 } & & $\%$ & $15.5 \%$ \\
\cline { 2 - 4 } & Moderate & Count & 71 \\
\cline { 2 - 4 } & \multirow{3}{*}{ High } & $\%$ & $61.2 \%$ \\
\cline { 2 - 4 } & & Count & 27 \\
\cline { 2 - 4 } & & $\%$ & $23.2 \%$ \\
\hline
\end{tabular}

Out of the 116 scans included in our study, we had 232 targets for primary tumour site and lymph nodes which have been followed up to twelve months duration post treatment. Overall tumour recurrence occurred in 53 targets out of total of 232, with a recurrence rate of $22.8 \%$, the recurrence rate for each NI-RADS category for the primary tumour site (Table 4) was: $3.9 \%(2 / 51)$ for NI-RADS 1 category, $17.6 \%$ (3/17) for NI-RADS 2a category, $18.2 \%$ (4/22) for NI-RADS $2 b$ category, and $76.9 \%$ (20/26) for NI-RADS 3 category.
Regarding the lymph nodes, the recurrence rates (Table 5) were: $3.8 \%(3 / 80)$ for NI-RADS 1 category, $7.1 \%$ (1/14) for NI-RADS 2 category, and $81.8 \%$ (18/22) for NI-RADS 3 category.

The recurrence rates for the NI-RADS categories combined for both the primary tumour site and lymph nodes were (Table 6): $3.8 \%(5 / 131)$ for NI-RADS 1 category, $19.6 \%(10 / 51)$ for NI-RADS 2 category, and $76.2 \%(38 / 48)$ for NI-RADS 3 category.

Table (5) Tumour recurrence for primary tumour site among NI-RADS categories correlated to the gold standard:

\begin{tabular}{|c|c|c|c|c|c|}
\hline & & \multicolumn{3}{|c|}{ Outcome for primary site } & \multirow[t]{2}{*}{ Total } \\
\hline & & & eg. & Pos. & \\
\hline \multirow{8}{*}{$\begin{array}{l}\text { NI-RADS } \\
\text { for } \\
\text { Primary } \\
\text { site }\end{array}$} & \multirow[t]{2}{*}{ NI RADS 1} & Count & 49 & 2 & 51 \\
\hline & & $\%$ & $96.1 \%$ & $3.9 \%$ & $100.0 \%$ \\
\hline & \multirow[t]{2}{*}{ NI RADS 2a } & Count & 14 & 3 & 17 \\
\hline & & $\%$ & $82.4 \%$ & $17.6 \%$ & $100.0 \%$ \\
\hline & \multirow[t]{2}{*}{ NI RADS 2b } & Count & 18 & 4 & 22 \\
\hline & & $\%$ & $81.8 \%$ & $18.2 \%$ & $100.0 \%$ \\
\hline & \multirow[t]{2}{*}{ NI RADS 3} & Count & 6 & 20 & 26 \\
\hline & & $\%$ & $23.1 \%$ & $76.9 \%$ & $100.0 \%$ \\
\hline \multirow{2}{*}{\multicolumn{2}{|c|}{ Total }} & Count & 87 & 29 & 116 \\
\hline & & $\%$ & $75.0 \%$ & $25.0 \%$ & $100.0 \%$ \\
\hline
\end{tabular}

Table (6): Tumour recurrence for neck lymph-nodes among NI-RADS categories correlated to the gold standard:

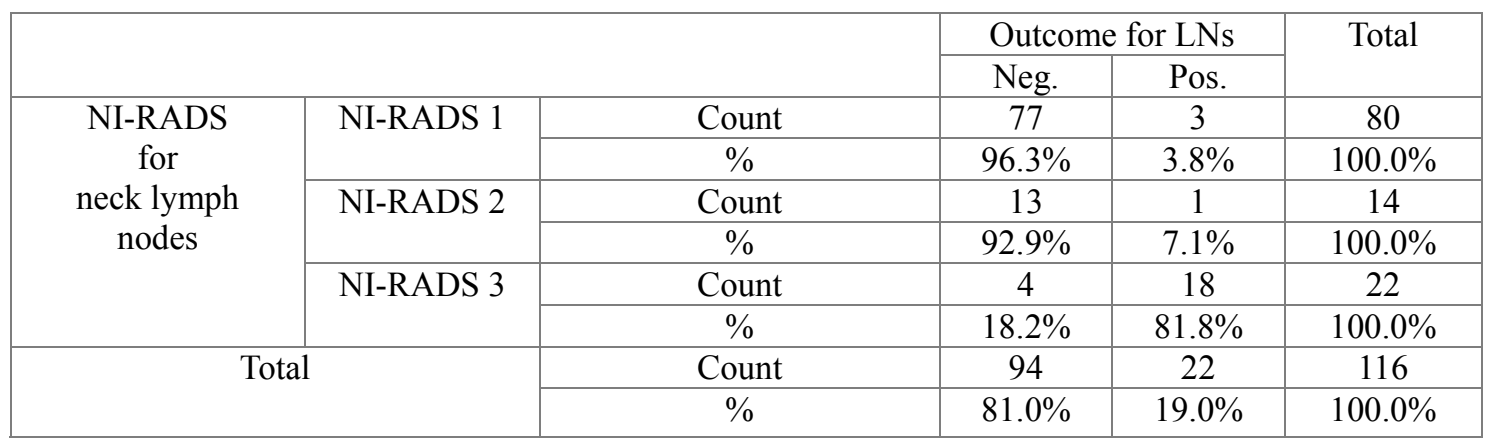


Table (7): Tumour recurrence for both primary tumour site and neck lymph-nodes among combined NI-RADS categories to the gold standard correlated to the gold standard:

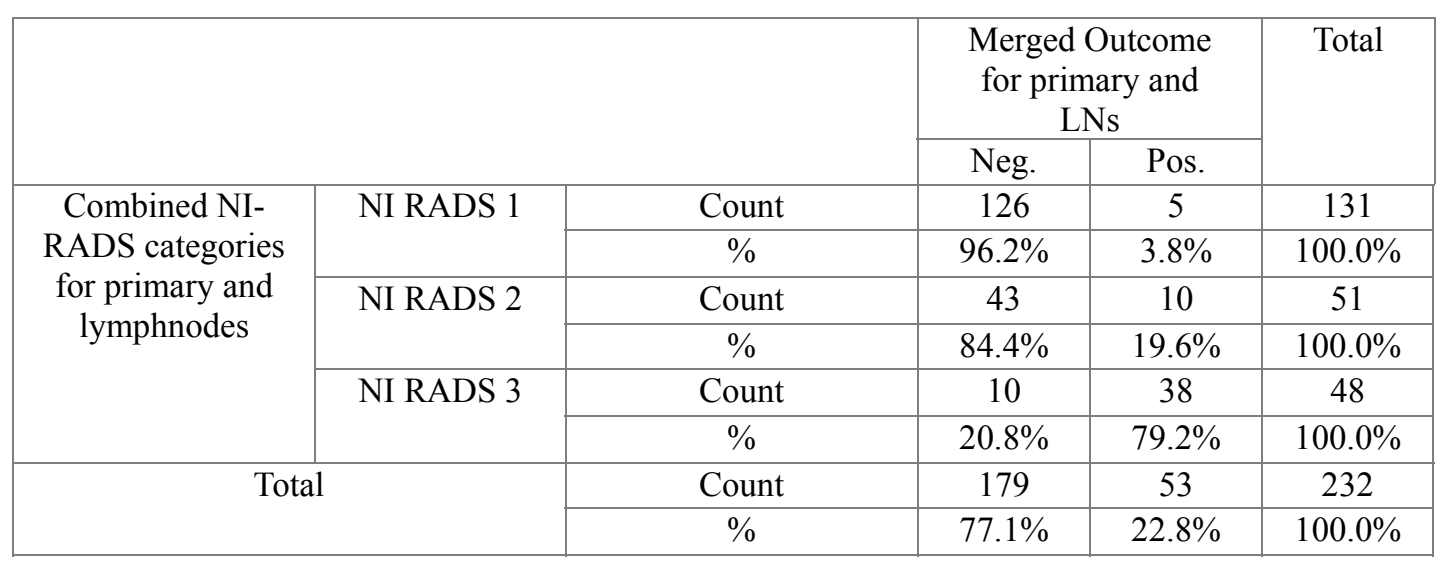

\section{DISCUSSION:}

The core of the ACR NI-RADS system is simplifying the complexity of the postoperative imaging findings in treated cases of head and neck cancers and summarizing these findings into four categories for the primary tumour site and for lymph nodes, with linked management recommendations for each category depending on the degree of suspicion for tumour residual/ recurrence. By this categorization we can obtain worldwide standardized reporting and follow up system for head and neck cancers treated patients and we can avoid unnecessary biopsies, or too close follow up for low risk cases, on the other hand close follow up/ assessment by PET CT or biopsy would be done at proper timing for early detection of recurrence in suspicious cases, avoiding unwarranted delays.

The performance of NI-RADS in our study showed significant discrimination between its different categories, with disease recurrence/persistence rates of $4 \%$ for NIRADS 1, 25\% for NI-RADS 2, and76.9\% for NI-RADS 3. A strong association between score and positive disease was found for primary site, lymph nodes, and all targets combined.

We compared our study with the initial study that evaluated the performance of NIRADS conducted by Kreiger et al., 2017which demonstrated significant discrimination between groups, with disease recurrence/persistence rates of $3.8 \%$ for NIRADS 1, 17.2\% for NI-RADS 2, and 59.4\% for NI-RADS 3.In our study we also had significant discrimination in-between different categories, yet we had higher rate of recurrence for NI-RADS 3 category. In our study we also had small erintervalin between the recurrence rates for NI-RADS $2 \mathrm{a}$ and $2 \mathrm{~b}$ categories, than the difference found by Kreiger et al., 2017 and this could be attributed to a lesser number of scans in our study.

NI-RADS 1 and 2 in general are considered negative studies, while NI-RADS 3 considered as a positive disease study, NIRADS 4 is pathologically proven cases or definitely progressing and these cases in our point of view in no need for statistical assessment, we focused on assessing NIRADS categories 1,2 and 3 as these what represent the complexity of imaging interpretation and the patient management is significantly altered according to them.

Limitations of this study include a relatively low number of the population.

\section{Conclusion}

The performance of the ACR NI-RADS reporting system and its linked management recommendations is excellent, with 
statistically significant discrimination in between the different NI-RADS categories for either the primary tumour site, lymph nodes and for both combined. The use of NIRADS can help to direct the management plans towards more proper options.

\section{REFERENCES:}

1. Vigneswaran N, and Williams M. (2014): Epidemiological Trends in Head and Neck Cancer and Aids in Diagnosis. Oral Maxillofac Surg Clin North Am. 2014; 26 (2): 123-141.

2. Marur S, and Forastiere A. (2016): Head and Neck Squamous Cell Carcinoma: Update on Epidemiology, Diagnosis, and Treatment. Mayo Clin Proc. 2016;91:38696.

3. Rudžianskasa V, Vaitkusb S, Rudžianskienè M, Kupčinskaitė-Noreikienè R, et al. (2014): Reirradiation for patients with recurrence head and neck squamous cell carcinoma: A single-institution comparative study. Medicina. 2014;50;92-99.

4. Felice F, Musio D, and Tombolini V.
(2015): Follow-Up in Head and Neck Cancer: A Management Dilemma. Advances in Otolaryngology 2015; 2015. http://dx.doi.org/10. 1155/2015/703450.

5. Gage K, Thomas K, Jeong D, Stallworth D and Arrington J (2017): Multimodal Imaging of Head and Neck Squamous Cell Carcinoma. Cancer Control. 2017; 24:172197.

6. Aiken A, Farley A, Baugnon K, Corey A et al. (2016): Implementation of a Novel Surveillance Template for Head and Neck Cancer: Neck Imaging Reporting and Data System (NI-RADS). Journal of the American College of Radiology. 2016; 13: 743-746.

7. Krieger D, Hudgins P, Nayak G, Baugnon K. (2017): Initial Performance of NI-RADS to Predict Residual or Recurrent Head and Neck Squamous Cell Carcinoma. AJNR Am J Neuroradiol, 2017; 38(6)1193-1199.

8. Aiken A, Rath T, Anzai Y, Branstetter B et al. (2018): ACR Neck Imaging Reporting and Data Systems (NI-RADS): A White Paper of the ACR NI-RADS Committee. J Am Coll Radiol,2018;15(8):1097-1108 


\section{Hanaa Abdel Kader Abdel Hameed, et al.,}

دور نظام البيانات و التقارير الخاص بتصوير الرقبة في التنبؤ بعودة ظهور سرطانات الخلايا الحرشفية في الوجه و الرقبة باستخدام طُرق التصوير بعودة المقطعي

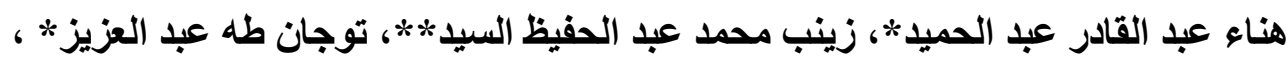

أحمد سامي عبد الرحمن* منار مأمون محمد عاشور

* * قسم الاشعة التشخصية، كلية الطب، جامعة عين شمس.

*** قسم علاج الأورام و الطب النووي، كلية الطب، جامعة عين شمس.

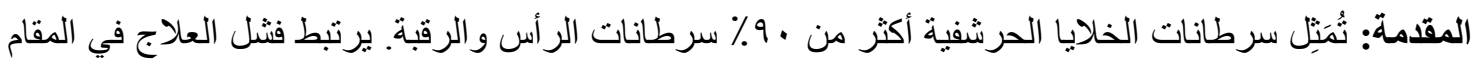

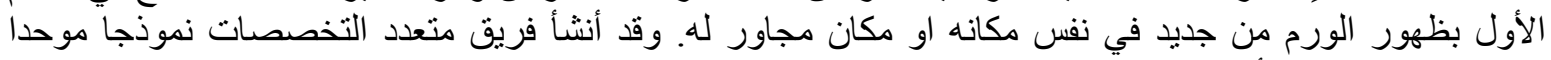

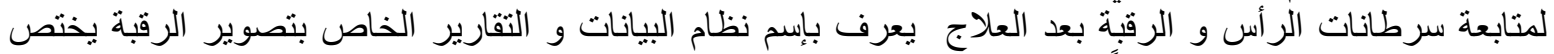
بتصنيف الفحوصات لمر احل طبقاً لدرجة التنبؤ لعودة ظهور الورة الورم.

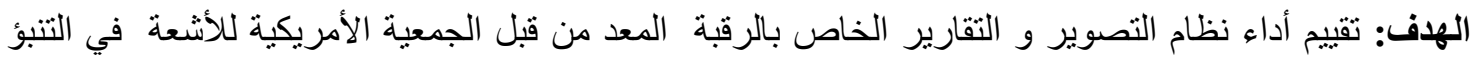

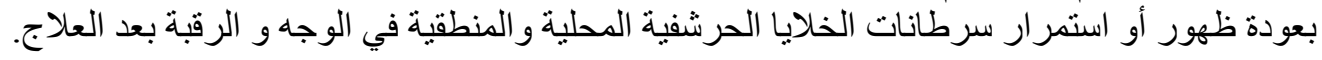

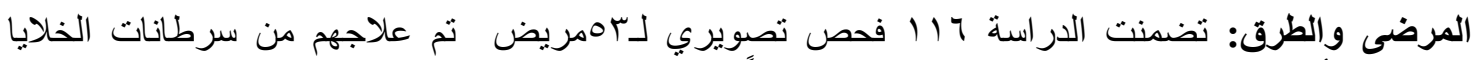

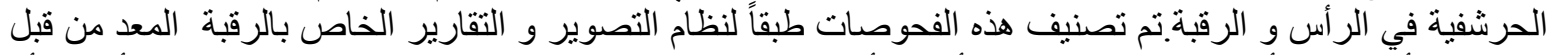

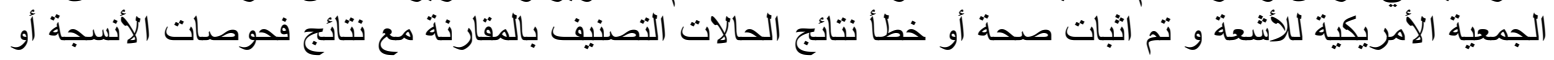
بفص متابعة بعد ثلاثة شهور.

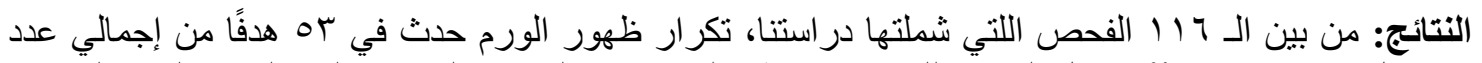

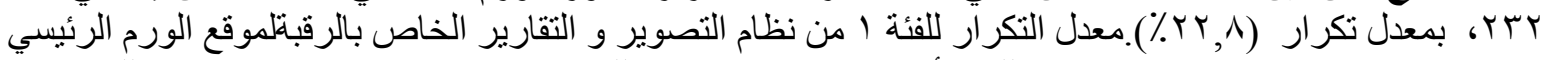
ب

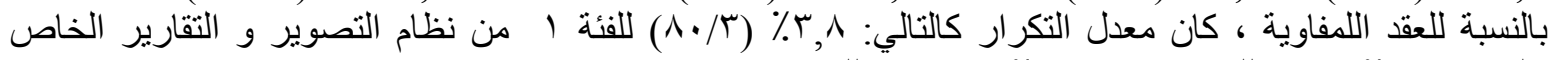

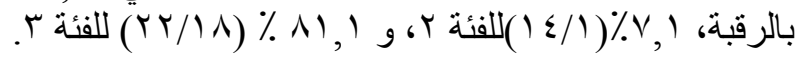

الخاتمة:أداء نظام التصوير و التقارير الخاص بالرقبة والتوصيات المرتبطة به ممتاز ، مع وجود تمبيز ذي دلالة إحصائية بين مختلف فئات هذا النظام. 